\title{
Adrenal Gland Schwannoma
}

National Cancer Institute

\section{Source}

National Cancer Institute. Adrenal Gland Schwannoma. NCI Thesaurus. Code C156944.

A rare schwannoma that arises from the adrenal medulla. 